\title{
Rx for Library Management
}

\section{Alvin C. Cage}

Traditionally, management practices in libraries have drawn extensively upon research and publication in the field of business management and its parent field, systems theory. This paper looks at recent developments in the field of systems theory that can improve library management practices by broadening the perspective in which these problems may be approached. In particular, the concept of organizational life cycles is discussed. A paradigm is developed for the application of its principles.

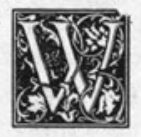

e have reached a time of, perhaps, unprecedented stability in the work forces of individual libraries. Relatively few jobs become available at the middle and upper levels of library management and when they do, it is often difficult to recruit effectively from outside the organization. Moreover, the work force is aging, but the majority of Americans are many years from retirement. Although the nature of their jobs has changed somewhat, many librarians are entrenched in their positions.

American libraries are no longer maintaining their former level of automatic self-renewal, which usually occurs when key administrators change. Dwindling financial resources have exacerbated the situation, retarding the development of innovative services. What effect are these events having on libraries? As they stand on the threshold of the Information Age, when so much will be asked of them, will the tried-and-true management practices of the past work for libraries, or are new and more powerful tools required?

Recent research in systems theory has provided a new perspective on dealing with management problems that is worthy of our consideration: the longitudinal study of organizations. Longitudinal systems theory represents a refreshing de- parture from conventional thinking by viewing an organization as a system that passes through distinctive stages of development not unlike those of a biological organism. In longitudinal systems theory, an organization is born, grows, matures and, like biological systems, has a natural tendency to decline with age and, yes, to die! This longitudinal perspective profoundly influences the nature of required management decisions.

\section{THE LIBRARY DOCTOR}

The organization manager, or library director, must be the organization's doctor and must consider the age and overall health of the patient. Just as a doctor would not automatically prescribe the same medicine for a child as for an adult, neither should the library manager respond uniformly to the symptoms of organizational malaise. To fully grasp the implications of this new thinking, we must briefly trace the evolution of management theory.

\section{EVOLUTION OF MANAGEMENT THEORY}

Traditional management practices have been substantially based on the works of classical organizational theorists such as Peter Drucker ${ }^{1}$ and Frederick Taylor. ${ }^{2}$ These theorists take the rational approach 
that management's job is simply to organize tasks for efficiency and effectiveness. They reason that, with proper training and careful employee selection, these properly organized tasks should be performed as directed, so long as competent people are assigned to do the work. Few would argue with this view.

Later organization theorists, however, added a new dimension to the understanding of management by focusing, not upon the rational ordering of tasks, but upon the individual's need for personal job satisfaction. This newer, naturalistic school of organizational theory proposed that, as Litterer suggests, "organizations rest . . . on the basic needs, both physical and emotional, of people. ${ }^{\prime \prime 3}$ The naturalistic school taught us that organizational goals will be most effectively accomplished when management considers how well they fulfill human, as well as organizational, needs. Naturalistic thought was most graphically reflected in the introduction of participatory management practices in libraries. Today, few librarians would consider themselves effective managers if they did not approach organizational problems from both the rational and humanistic (naturalistic) viewpoints.

\section{ADAPTATION AND EQUILIBRIUM}

The problem with traditional management theory is that it has tended to take a steady-state view of organizations. An organization is seen as naturally adaptive, that is, possessing within itself automatic, self-renewing mechanisms that return it to its desired state of equilibrium. Let's take a closer look at this concept.

"Adaptation concerns the modification of the organization or its components to fit or be adjusted to its environment. ${ }^{\prime 4}$ Through adaptation, an organization responds to change and maintains a desired state of organizational health known as equilibrium. An organization functioning properly is said to be in a state of equilibrium.

Figure 1 shows an organization operating indefinitely within an adaptive field that may be broad or narrow. The dotted line represents the passage of time into infinity. Over time, organizational behavior will depart from the ideal to a greater or lesser degree represented by the swing of the curves around the dotted line. Within every organization are natural adaptive mechanisms that will cause it to selfcorrect, or swing back toward equilibrium, also represented by the dotted line. In a system with few external influences, the swing, or adaptive field, is narrower. Organizations subject to considerable influences from without may regularly deviate further from equilibrium. Thanks to the Information Age, libraries may be moving into the broader adaptive field. Subject now to a marketplace in which information is gaining considerable economic value, libraries are finding commercial rivals for their services.

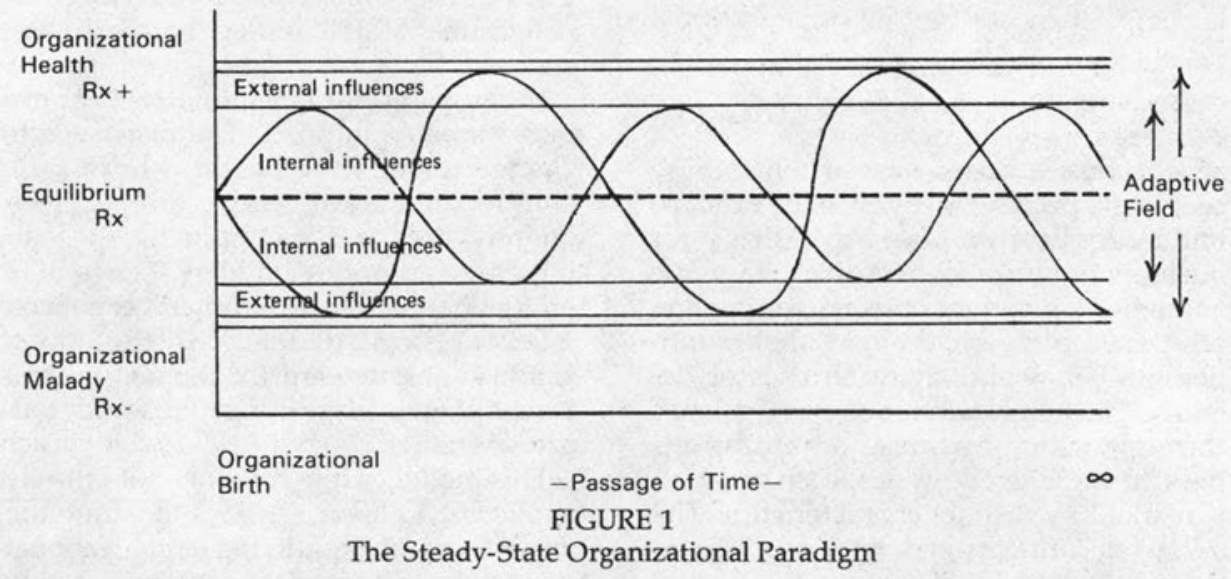




\section{TRADITIONAL VERSUS LONGITUDINAL THEORY}

Because of this steady-state view of organizations, traditional management theory has tended to take a rather onedimensional view of organizations that ignores their developmental paths. In longitudinal systems theory, however, the characteristics of adaptation are seen as varying at different stages in an organization's life cycle. ${ }^{5}$ We should note with some alarm that longitudinalists also view organizations as entropic, that is, possessing the tendency to decline over time (not represented on the diagram). This is a revolutionary thought when applied to libraries.

In traditional management theory, certain types of behavior within an organization are viewed as either good or bad. Longitudinal theory, however, takes quite a different approach. In longitudinal theory, the degree of organizational development determines whether the behavior is good or bad. Management, the longitudinalists say, must first determine the "stage" of an organization's development before taking any action. Why? Because what may appear to be a problem requiring corrective action may, in fact, be a solution-or at least a part of one. Through failure to perceive the specific stage or organizational development, the management doctor may diagnose a nonexistent malady and prescribe medicine that will make the patient sick! Or, as is more typically the case, management will fail to see the symptoms of organizational decline.

\section{ORGANIZATIONAL PARADIGMS}

Let's take a closer look at what these seemingly peculiar ideas mean by examining a paradigm proposed by Adizes ${ }^{6}$ for business organizations. Adizes is unique among organizational theorists in having developed a life-cycle model that identifies the behavioral characteristics of decline. ${ }^{7} \mathrm{He}$ has identified discrete stages through which business organizations pass during their life cycles, each of which is marked by distinct characteristics. The following summary of Adizes' model is intentionally simplified.
Courtship-a planning stage characterized by the flourishing of ideas during which the business' potential founders conceive their business plan but makes no real financial commitments.

Infancy-Financial commitments have gotten the organization underway; ideas decline as purpose narrows. Real productive activity begins.

Go-Go-The business has begun to succeed and confidence generates an expansion of activities and much free thinking with little formal planning.

Adolescence-As the organization expands, the lack of formal planning renders it unwieldy. Growth is modified to permit the development of structure. Policies and procedures begin to take on written form. Some formal short-range planning actually takes place.

Prime-The organization has reached an ideal stage of development. It has a high "results" orientation but remains open to innovation. Improvement in organizational structure has helped it to better understand its capabilities and to plan wisely.

Maturity-The system that worked so well in "Prime" has become institutionalized. It's more difficult to accomplish change now, which leads to occasional conflicts among staff.

Aristocracy-The organization has become tradition-bound. Little empires have been established by key staff, and there is strong resistance to change. There is much conflict for funds to expand existing empires but little incentive to develop new programs. Staff conflict, naturally, increases.

Bureaucracy-Systems, rules, and procedures are worshipped. The resistance to change renders the business unresponsive to its market, and profits, consequently, decline. Paranoia and scapegoating ensue as empire builders seek to hold on to what they have at other's expense.

Death-Formal dissolution of the organization, a just reward for the above-cited behavior, usually through business failure.

This model, while certainly not entirely applicable to libraries, does illustrate the importance of identifying organizational stages. Note that staff conflict, usually 
seen as a problem, was both healthy and necessary to the generation of ideas in the organization's infancy. Note, also, that the virtual absence of it, usually viewed as a sign of good management, portended disaster in "Aristocracy."

Although libraries are heavily institutionalized and do not pass through full life cycles of the type so dramatically illustrated by the Adizes model, it is highly probable that institutionalized organizations do possess at least some form of modified life cycle, which, if understood, could contribute significantly to making management decisions. Unfortunately, little of the work done to date in this area has focused on institutionalized organizations such as libraries, but in one study, Downs describes stages of growth and development appropriate to government agencies. He identifies three stages: in the first there is a struggle for autonomy, during which an agency is born out of growing concern or activity in a particular area, e.g., the separation of Education from the mammoth Department of Health, Education and Welfare within the federal government. Next, comes a productive period characterized by expansion and creativity. Finally, in deceleration, rules and procedures become elaborate and formalized, predictability replaces innovation, and the organization becomes familiarly bureaucractic. $^{8}$

\section{THE LIBRARY MODEL}

By synthesizing these models and drawing on commonly observed behavior, a paradigm of the library organizational life cycle may be developed. Figure 2 is a diagram of an organizational life-cycle model constructed for libraries. Because libraries, for now at least, have the protection of institutionalization, the diagram views them as permanent, represented by a closed circle. Libraries will move through their life cycles around the curve of the circle in either direction, depending

Honeymoon

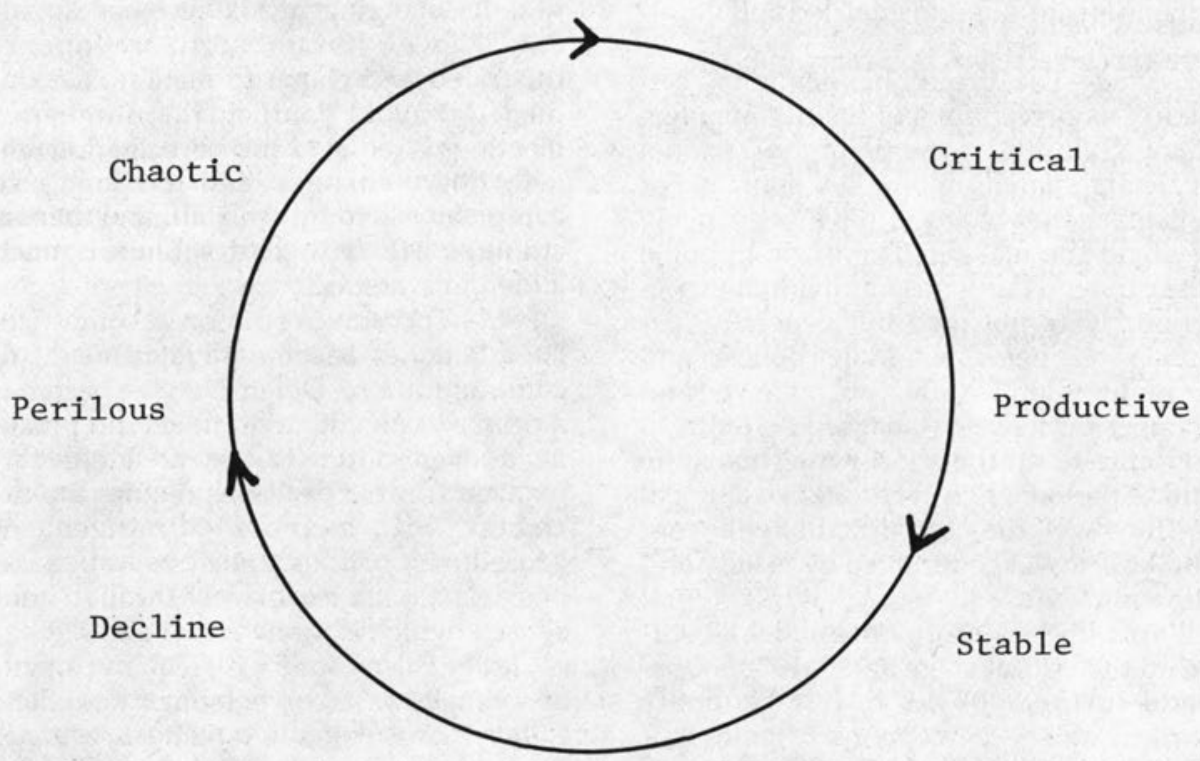

Bureaucratic

FIGURE 2

The Library Organizational Life Cycle 
upon whether they are getting better or worse.

The model, which is detailed below, might apply in a medium-sized to large academic library. In the library model, there are no birth or death stages, as in Adizes, because the library will continue to operate regardless of its organizational health, nor is there the autonomy stage from Downs' model. However, libraries are viewed as passing through recognizable organizational stages, the base stage coinciding with the appointment of a new director.

Honeymoon - the stage, usually following the appointment of a new director, characterized by uncertainty concerning policies, procedures, and organization, all of which are now subject to change. There will be lots of jockeying for position among key staff, who will fall over one another to demonstrate their desire to be "on the team." The honeymoon period is the time when it is easiest to gain cooperation and support; it is the golden opportunity for breaking up cliques and forming new alliances, but, if the new director comes from outside the organization, everyone is cautious and guarded and the atmosphere is tense.

Critical-The director has begun to "settle in" as perceptions of his/her management style and general organizational goals are shared among key staff; major organizational changes have been made or are in the making. There will be some disgruntled staff whose individual expectations were not met, but generally, enthusiasm is pervasive. Major policies and procedures long in effect are reviewed and changes formalized. Goal setting tends to concentrate on the short run. This is the critical period when everyone is waiting to see how well the new structure will work and how it will be received by faculty and student clientele.

Productive-The organization has survived the critical stage and, while not beyond further polishing, has generally worked by the perceptions of both staff and library clientele. Now, the climate is ripe for developing a high "results" orientation among staff. Ideas abound, and enthusiasm is relatively pervasive. The ability of the organization to generate productive outcomes, to serve as a vehicle for effective communication of ideas, and, in general, to operate with a sense of fairness toward staff has been demonstrated. Planning is beginning to expand out of the short range and into the long range.

Stable-Systems, policies, and procedures are highly efficient and quite effective. There are many meetings, but business is highly routine. Such cliques as may exist have become so stabilized that staff conflict is not readily apparent. Secondary lines of communication develop around personalities of key staff. Services are satisfactory but show little imagination or innovation and there is little incentive to extend them.

Bureaucratic-Precedent becomes the primary guideline for procedures and policies. Systems become complex and resistent to change. Committees are numerous and their meetings regular and formal. New programs are rarely initiated. Behavior is predictable and open staff conflict, virtually nonexistent. A feeling of satisfaction prevails.

Decline-Faculty and student disenchantment with the lack of responsiveness to changing needs becomes apparent. Newer library staff are openly frustrated and clique formation is rekindled. To avoid conflict, the number of meetings is reduced and participation limited. Policy changes tend to increase in complexity, though the number of real changes are few, and safeguards are added to systems.

Peril-Top administration becomes isolated. Cliques become a major means of communication. Defensiveness becomes a primary consideration in decision making as even routine matters are highly formalized (simple decisions require the exchange of memos). Changes in procedures, policies, and systems become possible almost exclusively through consensus, which is rarely achieved.

Chaos-Staff conflict is frequent, open, and usually based on personality conflicts rather than substantive matters. Morale, even among clerical staff, is low. The delivery of service is clearly secondary to organizational concerns that become consuming. Library users are understandably dissatisfied. The library has probably lost 
its ability to change from within, making the appointment of a new director imminent.

\section{USE OF THE MODEL}

Because the last three stages are similar, the model could be collapsed into fewer stages. The number of stages suggested, however, provides different symptoms that help identify the degree of urgency for getting the organization on track. Also while the model looks at the organization of an entire library, it could also be applied to a division of a department of a library of any appreciable size.

Appendix A illustrates the use of the model in library management. First, the manager-doctor uses the "symptoms" listed in column 2 to identify the age and condition of his patient (the stage in column 1). Once this has been determined with some certainty, he prescribes the corrective action suggested in column 3 . (The majority of libraries will fall into stages 3 through 5.) The goal of management is to move the organization forward or backward into the productive, or ideal, stage of development. This move should be made one stage at a time. Occasionally the patient should be reexamined to see if the remedy has worked and if the stage has changed. While no remedy is really necessary for a library in the productive stage of development, appendix A suggests a prescription for keeping it there.

The central theme in the use of the model is the analysis of behavior. Management should determine whether the typical organizational behavior is convergent (moving toward a common goal) or divergent (moving toward diverse goals). As the chart illustrates, there are times in the life cycle when convergent behavior is needed and times when divergent behavior is needed.

\section{CONCLUSION}

Libraries are indeed fortunate. They will endure, unlike biological organisms, which face certain, eventual death. Protected by institutionalization, they can also avoid the fate of business organizations that fail the test of the marketplace; the marketplace of ideas that we inhabit is more forgiving. Consequently, few libraries will be forced by circumstances into their most productive roles. But in a time of dwindling resources, burgeoning knowledge, and revolutionary changes in the management of information, we owe it to our users to do the best that we can.

\section{REFERENCES}

1. Peter Drucker, The Practice of Management (New York: Harper, 1954).

2. Frederick Taylor, Scientific Management (New York: Harper, 1957).

3. Joseph A. Litterer, Organizations: Structure and Behavior (New York: Wiley, 1963), p.4.

4. Paul S.Goodman and Associates, Change in Organizations (San Francisco: Josey-Bass, 1982), p.19.

5. Robert E. Quinn and Kim Cameron, "Organizational Life Cycles and Shifting Criteria of Effectiveness: Some Preliminary Evidence," Management Science 29:33 (Jan. 1983).

6. Ichak Adizes, How to Solve the Mismanagement Crisis (New York: Dow-Jones Irwin, 1979).

7. Ichak Adizes, "Organizational Passages-Diagnosing and Treating Lifecycle Problems of Organizations," Organizational Dynamics 7:3-25 (Summer 1979).

8. Anthony Downs, "The Life Cycle of Bureaus," in Inside Bureaucracy (San Francisco: Little and Rand Corp., 1967), p.296-309.

9. Fremont E. Kast and James E. Rosenzweig, Organization and Management: A Systems Approach (New York: McGraw-Hill, 1974), p.112.

\section{APPENDIX A: Rx DECISION CHART}




\section{APPENDIX A: CONTINUED}

Life-cycle Stage

Symptom(s)

1. Organization (continued)

2. Critical

3. Productive

4. Stable

5. Bureaucratic

6. Decline

7. Peril
Major organizational decisions have recently been made; staff morale generally improved but exceptions noticeable; policies and procedures are under review, but there is little or no long-range planning; key staff carry out delegated responsibilities with minimum instruction.

Few user complaints; unsolicited praise from user clientele received from time-to-time; most activity is planned rather than crisis-responsive; widespread staff enthusiasm toward work is evident; innovative thinking is visible at multiple tiers of the organization; chain of command is normally followed; staff conflict is usually over programs, not personalities; goals, both long- and short-range, are regularly established and accomplished.

Things work well, but there is little innovation; staff morale is good, but enthusiasm is lacking; little goal setting, or goals easily accomplished.

Policy manual too thick to close; precedent worshipped; there is much activity but little progress; goal setting is nonexistent or mechanical.

Faculty and students disenchanted; staff, especially newer ones, are openly frustrated; cliques hinder the conduct of business and negatively influence staff morale; meetings are avoided whenever possible and participation is limited; safeguards are added to policies and procedures, making them unnecessarily complex. Regular staff meetings are virtually nonexistent; few decisions are being made; these usually in defense of something; cliques are the major means of communication; even simple decisions require written justification. meetings and visit with faculty to generate ideas; concentrate on identification of major issues; make major decisions on organizational changes with minimal delay and implement as soon as possible. Seek to address causes of dissatisfaction among disgruntled staff; discuss services affected by major decisions with user clientele and refine decisions as necessary; establish, with broad input, at least one major goal.

Establish, expand, or improve formal communication with faculty and students; (start or improve a newsletter); increase proactive role of library committee; institute staff development programs and regular personnel evaluations; make major changes slowly and deliberately.

Increase innovation by establishing more challenging goals; reassign "stale" staff to new positions; establish a new department or program, if necessary, by consolidating or eliminating older ones; fill key vacancies from outside the organization.

Challenge "sacred cows"; institute zero-based budgeting; appoint reorganization committee. Set challenging goals.

Seek the assistance of an outside consultant in identifying chief problem areas and possible solutions (some key staff changes will almost certainly be necessary); concentrate on major problems and be ready to make hard decisions; reorganization is likely needed.

Same as 6, but the urgency is greater. 


\section{APPENDIX A: CONTINUED}

Life-cycle Stage

8. Chaos
Symptom(s)

Open staff conflict; low morale; service considerations are secondary to personal considerations; many complaints from clientele; all change or suggestion of change is highly threatening.
$\mathrm{Rx}$

Same as 6, but time has about run out. 